\title{
COMPARATIVE STUDY OF SOIL FERTILITY BASED ON SFM \\ COMPUTATIONAL MODEL FOR IB-INW AND IC-HAPI ZONE
}

\author{
JYOTI SIHAG ${ }^{1}$, DIVYA PRAKASH ${ }^{2 *}$ \& PARUL YADAV ${ }^{3}$ \\ ${ }^{1,2}$ Department of Chemistry, Amity School of Applied Sciences, \\ Amity University, Rajasthan, Jaipur, India \\ ${ }^{3}$ Department of Microbiology, Amity Institute of Microbial Technology, \\ Amity University Rajasthan, Jaipur, India
}

\begin{abstract}
In agriculture, soil is a critical component. This study compares the fertilization status of IC-HAPI zone with neighbouring IB-INW zone in agricultural land and waste land categories. IB-INW zone and IC-HAPI zone located in Rajasthan, India, were selected, with two different agriculture productions. Soil contents, calcium carbonate, CEC, pH, $E C, O C, N, P, K, Z n, F e, C u$ and $M n$ were compared. The fertilization status difference in soil of IB-INW and IC-HAPI zone was evaluated using the deterioration index (DI). Compared to soil of IB-INW zone, overall DI values of $+288.2 \%$ (FLS) and $+274.75 \%(W L S)$ were observed in soil of IC-HAPI. In the present study, $-45.16 \%$ (FLS) and $-58.45 \%$ (WLS) DI value of calcium carbonate were analysed in IC-HAPI. In farmland soil, positive DI values of nitrogen and phosphorus $+25.25 \%$ and $+24.23 \%$ were observed, respectively. While in case of nitrogen and phosphorus, positive $+16.83 \%$ and $+46.04 \%$ DI values were analysed in wasteland soil of IC-HAPI. The SFM model showed the deficiency of nitrogen, phosphorus and organic carbon were more pronounced in both zones. Model helps to predict soil fertilization status, and is able to solve nutrient related problems by micro-organisms. These micro-organisms can help to enhance and maintain the soil fertility and crop yield in the IC-HAPI and IB-INW zone. This experiment will help and encourage to researchers, agronomists or farmers, who are interested in evaluation of the agronomic, nutrient management and soil fertility management to sustain present and future agriculture. In this study, we calibrate the comparison of soil parameters as a tool for understanding and evaluating the fertilization status relationship between IB-INW and IC-HAPI zone of Rajasthan also, using a computational model.
\end{abstract}

KEYWORDS:SFM Model, DI \& Micro-Organisms

Received: May 10, 2019; Accepted: May 30, 2019; Published: Jul 03, 2019; Paper Id.: IJMPERDAUG201949

\section{INTRODUCTION}

IC-HAPI zone is a widely spread sea of sand. It covers $82475 \mathrm{~km}^{2}$ area in Rajasthan province. Mainly found vegetations of this area are Aak (Calotropis procera), Khimp (Leptadenia pyrotechnica), Ber (Ziziphus mauritiana) and Karira (Capparis decidua). The IC-hyper arid partial irrigated zone is one of the most seriously poor vegetation (desertified) areas in Rajasthan province, India. A very little part of this area has water supply, which makes the cultivation of wheat and mustard possible. Most of area is dependent on rain for water. If it rains, farmers grow Bajra (Pennisetum glaucum), Guar (Cyamopsis tetragonoloba), Moth (Vigna aconitifolia) and Chana (Cicer arietinum). On the other hand, neighbor IB-INW zone, which is just next to ICHAPI zone, is much more suitable for agriculture. This zone covers an area of $20634 \mathrm{~km}^{2}$. The IB-INW zone has mainly two districts namely Sri Ganganagar and Hanumangarh. This area is so rich in agriculture that Sri 
Ganganagar is known as the "food basket" of Rajasthan.

Compared on the bases of agricultural production, both neighbor zones have day-night difference. Agricultural fields are the backbone of economy and ecology of any developing country. "Soil" is the main content, rather the most important content, which directly effects the agricultural production in terms of quality as well as quantity. Soil fulfills the basic needs and nutrients requirements of crops. In order to understand the difference of production in both the discussed zones, study of their soil properties can play a very important role. So, the soil of each zone is mainly divided into two types i.e. FLS (Farm land soil) and WLS (Waste land soil), this makes four categories: IB-INW(FLS), IB-INW(WLS), ICHAPI(FLS) and IC-HAPI(WLS). The objective of this paper is to compare the soils of IB-INW zone and IC-HAPI zone on chemical and physical parameters. So in this study, FLS of IC-HAPI is compared with FLS of IB-INW and WLS is compared with WLS of IC-HAPI. Data of physicochemical parameters of IC-HAPI (Sihag et al., 2019) and IB-INW are taken from previously published paper.

For many decades, farmers have focused on chemical fertilizer and pesticides for enhancement of crop yields and soil fertility. Numerous studies have demonstrated that the use of chemical fertilizer and pesticides has contributed to improve crop production. However, excessive use of chemical fertilizer and pesticides have shown hazardous effect to soil ecosystem, human and plant health, also resulted in many environmental problems and degradation of soil fertility (Isin et al., 2007). The World Health Organization has reported that pesticides are negatively affecting human health in several million cases of world (WHO, 1990). Chemical fertilizers are not only negatively affecting human health but are also responsible for soil, air and water pollution (Savci, 2012; Sonmez et al., 2007; Atilgan et al., 2007; Shaviv, 2000; Thomsen et al., 1993; Fraters et al., 1998; Alva et al., 2003; Camargo et al., 2006; Bakhsh et al., 2007; Yu et al., 2007). Bio-fertilizer and bio-pesticides are a better option because of their non-hazardous effect, eco-friendly nature. Both are contributing greatly to improve grain production. Bio-fertilizer can play a key role in nutrient cycling and potentially affect nutrient retention/accumulation when applied in soil. Bio-fertilizer can shows positive environment impacts on poor agricultural site, agricultural site, crop production and soil ecology of Rajasthan. Micro-organisms can improve soil fertility, because they are able to provide organic matter to soil (He et al., 2003; Xue et al., 2007; Davidson et al., 1993).

Condition and quantity of using micro-nutrients can be easily defined with the help of model. Recently, many models have been developed and used for agriculture field and soil management (Sihag et al., 2019). Machine learning was widely applied to agriculture issues. Random forest algorithm was used for data prediction in model. Random Forests was proposed by Breiman in 2001, which add an additional property of randomness to bagging. In addition to constructing each tree using a different sample of the data, random forests change how the trees are constructed. In normal trees, each node is split using the best split method among all variables while in a random forest algorithm, each node is split using the best among a subset of predictors, which are randomly chosen at that node. This somewhat counter-intuitive strategy turns out to perform very accurate as compared to many other classifiers, and is robust against over fitting problems which generally occur in these algorithms. It is very user-friendly, as it has only two key parameters (the number of variables in the random subset at each node and the number of trees in the forest), and maximum times it is not very sensitive to their values. For the implementation of Random Forest using python, sklearn provides a module which makes implementation very easier. The model can also suggested treatment of nutrient deficiency by micro-organisms. If the soil was non-fertile, then model can able to suggest which and how much bio-fertilizer we needed to make that soil "fertile" in minimum cost. 
The aim of this work is to analyse the actual problem of soil and also maintain its fertility in both zones. In this study, we compared the soil physico-chemical parameters like $\mathrm{pH}$, electrical conductivity, organic carbon, the availability of nutrients $(\mathrm{N}, \mathrm{P}, \mathrm{K})$, trace $\left(\mathrm{Fe}, \mathrm{Mn}, \mathrm{Cu}, \mathrm{Zn}\right.$ ) elements, sand, silt, clay, $\mathrm{CEC}$ and $\mathrm{CaCO}_{3}$ between IB-INW and IC-HAPI zone of Rajasthan also, using a computational model.

\section{MATERIALS AND METHODS}

\section{Study Area}

In this paper, we compared the soil of two neighbouring zone i.e. IB-INW and IC-HAPI zone of Rajasthan. The position of both studied zone is shown in Figure 1. Different agro-climatic condition has been found in both studied IBINW and IC-HAPI zones. The climate of both zones is hot and arid. Small difference has been observed in temperature for IB-INW and IC-HAPI zone. The mean minimum temperature for IB-INW and IC-HAPI zone are $6.3^{\circ} \mathrm{C}$ and $5.5^{\circ} \mathrm{C}$, respectively. The mean maximum temperature for IB-INW and IC-HAPI are $41.7^{\circ} \mathrm{C}$ and $40.5^{\circ} \mathrm{C}$, respectively. The average annual rainfall of IB-INW zone is $225 \mathrm{~mm}$ while $273.05 \mathrm{~mm}$ is annual rainfall recorded in IC-HAPI zone.

\section{Physico-Chemical Parameters}

In both zones, the soil fertility was evaluated by same methods (Sihag et al., 2019).

\section{Statistical Analysis}

The deterioration index values were evaluated by using of Microsoft Excel 2007. The DI measured the extent of change in soil parameters under IC-HAPI zone and compared it to IB-INW zone (reference). The deterioration index was measured as the difference between individual soil parameter of IC-HAPI zone compared to reference values of same soil parameters under IB-INW. Soil parameters considered for DI calculation were sand, silt, clay, cation exchange capacity, calcium carbonate, $\mathrm{pH}$, electrical conductivity, organic carbon, organic matter, nitrogen, potassium, phosphorus, zinc, iron, copper and manganese. The deterioration index was calculated using the equation below (Ekanade, 1991):

$$
\mathrm{DI}=\left[\left(\mathrm{X}_{\mathrm{IB}-\mathrm{INW}}-\mathrm{X}_{\mathrm{IC}-\mathrm{HAPI}}\right) / \mathrm{X}_{\mathrm{IB}-\mathrm{INW}}\right] * 100
$$

Where, $\mathrm{X}_{\mathrm{IB}-\mathrm{INW}}=$ mean value of soil parameter in IB-INW zone (reference site) and $\mathrm{X}_{\mathrm{IC}-\mathrm{HAPI}}=$ mean value of soil parameter in IC-HAPI zone. Negative DI values indicate soil increasing order and positive values indicate decreasing order of soil parameter in IC-HAPI as compared to IB-INW zone.

\section{SFM Model}

Learning was widely applied to agricultural issues. Machine Learning was used to analyse and process large data sets and establish useful classifications and do predictions from the data sets. The overall goal of this model is to predict the fertility of soil. To start with any machine learning model, it was first necessary to bring all the data together. The data used for this proposed work were obtained from IB-INW and IC-HAPI zone of Rajasthan in India. The data were taken in sixteen input variables. The variables were $\mathrm{pH}, \mathrm{EC}, \mathrm{OC}, \mathrm{OM}, \mathrm{N}, \mathrm{P}, \mathrm{K}, \mathrm{Zn}, \mathrm{Fe}, \mathrm{Cu}, \mathrm{Mn}$, Sand, Silt, $\mathrm{Clay}_{2} \mathrm{CaCO}_{3}$ and CEC. In SFM, data was passed through mainly three phases i.e. training phase, Prediction phase, and Analysis phase. In the training phase, the data was collected and pre-processed. The pre-processed data was used for prediction using Random Forest Algorithm. Then, the model was trained with the pre-processed data. In the prediction phase, the fertility was predicted using trained model. In the analysis phase, those data are analysed whose predicted fertility was "Nonfertile". 


\section{RESULT AND DISCUSSIONS}

\section{Comparison in FLS Physical Parameter Between IB-INW and IC-HAPI Zone}

The sand content varied from 39.7 to $60.4 \%$ and 77.2 to $90.7 \%$ with mean values 53.15 and $83.85 \%$ (Table 1) in IB-INW and IC-HAPI zone, respectively. The sand content in IC-HAPI zone was higher than IB-INW zone resulting increasing -57.76 percent DI value calculated for IC-HAPI zone. However, silt content was observed from 11.6 to $26.4 \%$ and 1.4 to $18 \%$ in IB-INW and IC-HAPI zone, respectively. And clay content in IB-INW and IC-HAPI zone were ranged from 19.6 to $36.8 \%$ and 4.7 to $13.8 \%$, respectively. In case of silt and clay content, the decreasing DI values $+71.50 \%$ and $+58.85 \%$ was observed for IC-HAPI zone. DI value of calcium carbonate -45.16 percent was analyzed in IC-HAPI zone. The cation exchange capacity ranged from 15 to $31.45 \mathrm{meq} / 100 \mathrm{~g}$ in IB-INW zone while in IC-HAPI zone, range assessed from 3.27 to 16.27 meq/100. For cation exchange capacity, the positive DI $+68.46 \%$ were measured in IC-hyper arid partial irrigated zone.

\section{Comparison in WLS Physical Parameter Between IB-INW and IC-HAPI Zone}

For IB-INW zone; sand, silt and clay contents varied from 71.8 to $86.5,5.6$ to 12.2 and 7 to 16.8 percent, respectively. While 84.3 to $96.2,1.1$ to 9.5 and 2 to 7.3 percentile ranges were measured for sand, silt and clay content of IC-HAPI zone soil. So, the decreased +40.22 and $+55.62 \%$ DI values in silt and clay were examined for IC-HAPI. However, in case of sand content increased $-11.12 \%$ DI value was examined in IB-INW. The calcium carbonate was ranged from 1 to 3.4 and 0 to $16.19 \%$ in IB-INW and IC-HAPI zone, respectively. Similarly, in increasing order -58.45 percent deterioration indexes was observed for calcium carbonate in IC-HAPI soil. The cation exchange capacity was varied from 26.11 to 12 and 1.2 to $7.36 \mathrm{meq} / 100 \mathrm{~g}$ in IB-INW and IC-HAPI soil samples, respectively. The positive DI $+77.52 \%$ were calculated for cation exchange capacity in IC-HAPI with respect to IB-INW zone.

\section{Comparison in FLS Chemical Parameter Between IB-INW and IC-HAPI Zone}

From IB-INW to IC-HAPI, pH of soil varied from 7.23 to 8.44 and 6.52 to 9.48 ranges. The $\mathrm{pH}$ in IB-INW and IC-HAPI; 68.43 and 28\% soil were found in neutral (normal) (6.5 to 8) range. While 68 and 31.57\% soil of IC-HAPI, IBINW zone was found in moderately alkaline range. Resulting, increasing DI value of $\mathrm{pH}-5.97$ percent was measured in ICHAPI zone as compared to IB-INW zone. The electrical conductivity of IB-INW and IC-HAPI were ranged from 0.25 to 2.64 and 0.1 to $1.58 \mathrm{dS} \mathrm{m}^{-1}$, respectively. The soil electrical conductivity increases with the increased concentration of ions (Tale et al., 2015). The data were revealed that $86.84 \%$ soil of IB-INW zone showed normal electrical conductivity. While $96 \%$ soil of IC-HAPI zone was analyzed in normal range. Only $5.27 \%$ soil of IB-INW zone was analyzed above $2.5 \mathrm{dS} \mathrm{m}^{-}$

${ }^{1}$. Remaining 7.89 and $4 \%$ soil of IB-INW and IC-HAPI were observed in the range of 0.8 to $1.6 \mathrm{dS} \mathrm{m}^{-1}$, respectively. Decreasing DI value of EC +42.37 percent was measured in IC-HAPI.

For IB-INW and IC-HAPI zone, soil organic carbon was assessed from 0.12 to 1.02 and 0.01 to $0.74 \%$, respectively. Soil OC in 55.26\% IB-INW was found in low range. However, low organic carbon $(<0.50 \%)$ was observed for 90\% IC-HAPI zone. Remaining 42.11 and $2.63 \%$ soil of IB-INW were examined in medium and high organic carbon range, respectively. Soil organic carbon is an important key of soil fertility that is closely related to land and crop production (Lal, 2009). The organic carbon DI value in this study

+42.50 percent was examined in IC-HAPI. Regarding soil organic matter, deterioration indices value $+42.64 \%$ was observed in IC-HAPI zone. Soil organic matter is essential for crop production because, it provides nutrients and 
modifying physical properties of soil (Kononova, 1961). Range of soil nitrogen was varied from 201 to 278 and 75 to 278 $\mathrm{kg} \mathrm{ha}^{-1}$ in IB-INW and IC-HAPI zone, respectively. Low nitrogen status was assessed in farmland soil of both studied zones. Low nitrogen concentration directly affects plant growth, because it is primordial part of chlorophyll and played important role to formation protein and amino acid (Hodges et al., 1996). Nutrient nitrogen is a dynamic nutrient and used in large amount by all living organisms compared to other macro-nutrient. Compared to IB-INW, decreasing DI value +25.25 percent was calculated for nitrogen in IC-HAPI soil. Soil phosphorus was varied from 7 to 56 and 3 to $35.6 \mathrm{~kg} \mathrm{ha}^{-1}$ for IB-INW and IC-HAPI zone, respectively. Soil phosphorus concentration was assessed in low, medium and high range for 21.05, 57.90 and 21.05\% IB-INW soil, respectively. While 40, 36 and 24\% soil assessed in low, medium and high range, respectively. Phosphorus plays important role in many important process like cell division, respiration, growth process, photosynthesis and plant development process of plant (Hodges et al., 1996). According to calculation the DI value of phosphorus nutrient, +24 .23percent was calculate in IC-HAPI. Nutrient potassium concentration was varied from 252 to 484 and 107 to $480 \mathrm{~kg} \mathrm{ha}^{-1}$ in FLS of IB-INW and IC-HAPI zone, respectively. For potassium nutrient, the positive DI value $+38.56 \%$ was observed in IC-HAPI zone. Crop growth point of view potassium is important in protein synthesis, photosynthesis, water regulation and carbohydrate synthesis (Hodges et al., 1996).

Micronutrient zinc concentration was available from 0.20 to 0.73 and 0.04 to $1.30 \mathrm{ppm}$ in IB-INW and IC-HAPI zone, respectively. Deficient availability of zinc nutrient was found in $36.84 \%$ soil of IB-INW zone. While $66 \%$ soil of ICHAPI zone was assessed in deficient $(<0.6 \mathrm{ppm})$ range. Zinc deficiency is affected by many processes like transformation of carbohydrates; oxidation and synthesis of auxin indole acetic acid as well as it affected functions of plant enzymes (Hodges et al., 1996). The decreased $+8.92 \%$ DI in zinc concentration was examined for IC-HAPI as compared to IB-INW zone. Similarly, range of iron concentration varied from 2.9 to 6.4 and 1 to $9.1 \mathrm{ppm}$ in soil of IB-INW and IC-HAPI zone, respectively. The iron concentration was observed in sufficient (>4.5 ppm) range for $81.58 \%$ IB-INW and 58\% IC-HAPI zone. Here, increasing DI value of iron $-8.76 \%$ was analyzed in IC-HAPI zone. The deficiency of copper was not found in farmland soil of IB-INW, while $26 \%$ FLS of IC-HAPI was assessed below the $0.2 \mathrm{ppm}$ in deficient range of copper. In ICHAPI, positive DI value of copper $+14.28 \%$ was measured. Hundred percent soil of IB-INW zone were observed sufficient availability in manganese nutrient. But $6 \%$ soil of IC-HAPI was assessed in deficient range of manganese. Soil pH, soil moisture and organic matter affected availability of manganese. Manganese is constituent of some plant enzymes and activate plant enzyme in many process like metabolisms, photosynthesis, protein synthesis and respiration (Hodges et al., 1996). Although, the negative DI value of manganese $-31.71 \%$ was observed in IC-HAPI soil.

\section{Comparison in WLS Chemical Parameter Between IB-INW and IC-HAPI Zone}

Range of $\mathrm{pH}$ varied from 7.24 to 8.39 and 7.42 to 8.73 in WLS of IB-INW and IC-HAPI zone, respectively. Soil $\mathrm{pH}$ in $52.64 \%$ IB-INW and $16 \%$ IC-HAPI was observed in neutral (normal) range while $47.36 \%$ IB-INW and $84 \%$ ICHAPI analyzed in moderately alkaline nature. The increasing $-5.38 \%$ DI value was evaluated for $\mathrm{pH}$ in IC-HAPI. For IBINW and IC-HAPI zone, the EC varied from 0.13 to 0.50 and 0.02 to $1.2 \mathrm{dS} \mathrm{m}^{-1}$, respectively. Normal range $\left(<0.8 \mathrm{dS} \mathrm{m}^{-1}\right)$ of electrical conductivity was examined for whole IB-INW and 96\% IC-HAPI zone. While $4 \%$ soil of IC-HAPI was assessed in 0.8 to $1.6 \mathrm{dS} \mathrm{m}^{-1}$. Compared to IB-INW, the positive $+23.33 \%$ DI value was analyzed for EC in wasteland soil of IC-HAPI.

The organic carbon varied from 0.09 to 0.44 and 0.03 to $0.73 \%$ in IB-INW and IC-HAPI zone, respectively. Similarly, nitrogen nutrient was varied from 132 to $260 \mathrm{~kg} \mathrm{ha}^{-1}$ and 96 to $274 \mathrm{~kg} \mathrm{ha}^{-1}$ in soil of IB-INW and IC-HAPI zone, 
respectively. For whole IB-INW zone, low organic carbon status and nitrogen concentration were examined. Low range of organic carbon was found in 96\% IC-HAPI zone. According to economic standpoint, nitrogen is vital nutrient element in soil organic matter (Allison, 1973). Agricultural crop plants have a higher $\mathrm{N}$ necessity as compared to forest or natural plant communities (Date, 1973). In organic carbon content and nitrogen nutrient respectively, positive DI value $+21.05 \%$ and $+16.83 \%$ were examined in WLS of IC-HAPI zone. Organic matter is regarded as an important factor indicator of soil quality (Riley et al., 2008). Soil organic matter is responsible for making the physical environment of soils suitable for the crops development (Campbell, 1978). Soil phosphorus varied from 7 to $47 \mathrm{~kg} \mathrm{ha}^{-1}$ and 1.8 to $20.9 \mathrm{~kg} \mathrm{ha}^{-1}$ for IB-INW and IC-HAPI zone, respectively. Phosphorus concentration in $36.84 \%$ and $52.63 \%$ IB-INW zone was measured in low and medium range, respectively. While $78 \%$ and $22 \%$ soil of IC-HAPI zone assessed in low and medium range, respectively. Remaining $10.53 \%$ WLS of IB-INW was found above $25 \mathrm{~kg} \mathrm{ha}^{-1}$. In decreasing order, $+46.04 \%$ DI was measured for phosphorus concentration in IC-HAPI. Available potassium was found from 200 to $374 \mathrm{~kg} \mathrm{ha}^{-1}$ and 70 to $416 \mathrm{~kg} \mathrm{ha}^{-1}$ for IB-INW and IC-HAPI zone, respectively. In which, 86.84\% IB-INW and 64\% IC-HAPI showed medium range. Remaining $13.16 \%$ and $12 \%$ wasteland soil showed potassium in high rage for IB-INW and IC-HAPI zone, respectively. Deterioration index value for soil potassium $+23.19 \%$ was measured in IC-HAPI.

Zinc concentration varied from 0.19 to 0.68 and 0.23 to $0.89 \mathrm{ppm}$ in IB-INW and IC-HAPI zone, respectively. In which, 73.68 percent IB-INW and 76\% IC-HAPI zone was measured in deficient range, while remaining soil of both zones was present in sufficient range $(>0.6 \mathrm{ppm})$ of zinc. The DI of zinc, $-9.30 \%$ was observed in IC-HAPI. Range of micronutrient iron was varied from 1.3 to $6.4 \mathrm{ppm}$ and 2.4 to $6.2 \mathrm{ppm}$ in wasteland soil of IB-INW and IC-HAPI zone, respectively. The deficiency was observed in $60.53 \%$ IB-INW and 76\% IC-HAPI soil for iron nutrient. In plants, iron is essential to chlorophyll production and activation of many enzymes such as catalase, cytochrome, fumaric hydrogenase and oxidase (Hodges et al., 1996). Deterioration index value for iron nutrient $-3.22 \%$ was measured in IC-HAPI. Range of copper was varied from 0.21 to $0.56 \mathrm{ppm}$ and 0.11 to $0.45 \mathrm{ppm}$ in WLS of IB-INW and IC-HAPI zone, respectively. Soil copper concentration in whole IB-INW was observed under sufficient range while $32 \%$ soil of IC-HAPI zone assessed in deficiency. Deficiency of copper can impact on seed production, respiration, photosynthesis, disease resistance, cell wall metabolism, nitrogen metabolism and carbohydrate distribution (Hodges et al., 1996). The decreasing (positive) DI of copper nutrient $+28.57 \%$ was examined for IC-HAPI. Concentration of manganese micronutrient varied from 1.06 to 4.21 ppm and 0.2 to $4.8 \mathrm{ppm}$ in IB-INW and IC-HAPI zone, respectively. However, no manganese deficiency was observed for all examined sites of IB-INW while $22 \%$ soil of IC-HAPI zone assessed in manganese deficient range. For manganese, the positive DI value $+8.64 \%$ was examined in IC-HAPI.

\section{Data Analysis by SFM Model}

Data of samples were collected from the IB-INW and IC-HAPI (Sihag et al., 2019) region of Rajasthan and their fertility was predicted from our trained model. Then from the predicted results, the soil data which was non-fertile were taken for the analysis. The collected data was passed through our model in which, each row was iterated up to 'n' times till all the excess or deficient chemical properties were determined to make the soil fertile. In the results, negative values means that chemical was in excess in the soil and positive values means that chemical was deficient in the soil. According to model calculation, positive (+ve) values were observed for organic carbon, nitrogen, phosphorus and potassium parameter. That means, low availability of organic carbon content, essential nutrient (phosphorus, potassium and nitrogen) was observed in whole IC-HAPI soil (Figure 2). Similarly in IB-INW zone, deficiency was measured for organic carbon, nitrogen and phosphorus nutrient (Figure 3). 


\section{CONCLUSIONS}

We evaluated the comparison of soil fertilization status between IB-INW and IC-HAPI zone. Soil physicochemical parameters sand, silt, clay, calcium carbonate, CEC, pH, EC, OC, N, P, K, Zn, Fe, Cu and Mn of IB-INW were compared with that of IC-HAPI zone. The deterioration index (DI) was used to determine the soil fertility difference in IB-INW and IC-HAPI zone under farmland soil and wasteland soil. The positive DI value $+25.25 \%$ was observed in farmland soil of IC-HAPI zone for nitrogen nutrient. The increasing DI of iron and manganese $-8.76 \%$ and $-31.71 \%$ were analysed for FLS in IC-HAPI. In case of zinc and iron, respectively increasing $-9.30 \%$ and $-3.22 \%$ DI were assessed in wasteland soil of IC-HAPI.

Results of SFM model calculation suggested that nitrogen was the most deficient available nutrient $\left(<280 \mathrm{~kg} \mathrm{ha}^{-1}\right)$ in the soil of IB-INW and IC-HAPI zone. As well as low presence of organic carbon was observed in both zone. Deficiency of organic matter can improve by micro-organisms. Similarly, the phosphorus nutrient in $21.05 \%$ farm land area of IB-INW zone and 40\% of IC-HAPI zone were measured in deficient range. For supply of nitrogen and phosphorus nutrient in soil of both zones, model suggested that use bio-fertilizer like Azotobactor, Bacillus edaphicus, Enterobacter and Pseudomonas striata. Enterobacter and Pseudomonas striata micro-organisms help to mineralize organic phosphorus solubilize bound phosphorus and release soluble inorganic phosphate into soil. The supply of N, P nutrients in soils will be help to get better and highly crop yield in IC-HAPI zone as well as to sustain soil health in IB-INW zone, because nitrogen and phosphorus are essential nutrient for plant. The increase in essential nutrient is favourably associated with improvement in soil fertility and soil ecology stability.

\section{ACKNOWLEDGEMENTS}

Authors thank Hardik Gupta, Department of computer science, Amity school of Engineering \& Technology, Amity University Rajasthan, Jaipur (India) for helping in the model.

\section{REFERENCES}

1. Allison, F.E. (1973). Soil organic matter and its role in crop production., Elsevier New York.

2. Alva, A. K., Paramasivam, S., Graham, W. D., \& Wheaton, T. A. (2003). Best nitrogen and irrigation management practices for citrus production in sandy soils. Water, Air, \& Soil Pollution, 143, 139-154.

3. AtÕlgan, A., Coúkan, A., Saltuk, B., \& VeErkan, M. (2007). Antalya Yöresindeki Seralarda Kimyasalve Organik Gübre Kullan Õm Düzeylerive Olas ÕÇevre Etkileri. Ekoloji, 15(62), 37-47.

4. Bakhsh, A., Kanwar, R. S., Pederson, C., \& Bailey, T. B. (2007). N-source effects on temporal distribution of $\mathrm{NO}_{3} \mathrm{~N}$ leaching losses to subsurface drainage water. Water, Air, \& Soil Pollution, 181, 35 -50.

5. Camargo, J. A., \& Alonso, Á. (2006). Ecological and toxicological effects of inorganic nitrogen pollution in aquatic ecosystems: A global assessment. Environment International, 32, 831-849.

6. Campbell, C.A. (1978). Chapter 5 Soil organic carbon, nitrogen and fertility. Developments in soil science, 8, 173-271.

7. Date, R.A. (1973). Soil Biol. Biochem., 5, 5-18.

8. Davidson, E.A., \& Ackeman, I.K. (1993). Changes in soil carbon inventories following cultivation of previously untilled soils. Biogeochemistry, 20, 161-193. 
9. Ekanade, O. (1991). Degradation of the physical elements of the rural environment resulting from tree crops cultivation in the Nigerian cocoa belt. Singapore Journal of Tropical Geography, 12(2), 83-94.

10. Fraters, D., Leo, J. M., \& Wim, D. (1998). Nitrogen monitoring in groundwater in the sandy regions of the Netherlands. Environmental Pollution, 102, 479-485.

11. He, Z.L., Yang, X.E., Baligar, V.C., \& Calvert, D.V. (2003). Microbiological and biochemical indexing systems for assessing quality of acid soils. Adv. Agron, 78, 89-138.

12. Hodges, S. C., \& Crozier, C. (1996). Soil Fertility Basics. Soil science extension, North Carolina State University.

13. Isin, S., \& Yildirim, I. (2007). Fruit-growers' perceptions on the harmful effects of pesticides and their reflection on practices: The case of Kemalpasa, Turkey, Crop production, 26, 917-922.

14. Kononova, M.M. (1961). Soil organic matter: Its nature and its role in soil formation and in soil fertility. USSR Academy of Sciences and Pergamon Press, New York, USA.

15. Kumari, J. A., \& Rao, P. Effect Of Temperature On Soil Enzyme Urease Activity-Productivity.

16. Lal, R. (2009). Soil quality impacts of residue removal for bioethanol production. Soil and Tillage Research, 102, $233-241$.

17. Patel, P. H., Patel, N. P., \& Patel, P. L. Wavelet Based Analysis Of Soil Nutrients Of Surendranagar District, Gujarat, India.

18. Riley, H., Pommeresche, R., Eltun, R., Hansen, S., \& Korsaeth, A. (2008). Soil structure, organic matter and earthworm activity in a comparison of cropping systems with contrasting tillage rotations, fertilizer levels and manure use. Agr. Ecosyst. Environ., 124, 275-284.

19. Savci, S. (2012). Investigation of effect of chemical fertilizers on environment. APCBEE Procedia, 1, 287-292.

20. Shaviv, A.(2000). Advances In Controlled Release Fertilizers, Advances in Agronomy, 71, 1-49, Word Version, Before Printing.

21. Sihag, J., Prakash, D., \& Gupta, H. (2019).Soil Fertilization Status Assessment for IC-HAPI Zone of Rajasthan with SFM Computational Model. Advances in Intelligent Systems and Computing (Accepted).

22. Sihag, J., \& Prakash, D. (2019). A Review: Importance of Various Modeling Techniques in Agriculture/Crop Production. Advances in Intelligent Systems and Computing, 742, 699-707.

23. Sonmez, I., Kaplan, M., \&Sonmez, S. (2007). Investigation of Seasonal Changes In Nitrate Contents Of Soils And Irrigation Waters In Greenhouses Located In Antalya-Demre Region. Asian Journal Of Chemistry, 19(7), 5639-5646.

24. Tale, K. S., Ingole, D. S. (2015). A Review on Role of Physico-Chemical Properties in Soil Quality. Chem Sci Rev Lett., 4(13), 57-66.

25. Thomsen, I. K., Hansen, J. F., Kjellerup, V., \& Christensen, B. T. (1993). Effects of cropping system and rates of nitrogen in animal slurry and mineral fertilizer on nitrate leaching from a sandy loam. Soil Use and Management, 9, 53 -58.

26. WHO (1990). The public health impact of pesticides use in agriculture. World Health Organisation, Geneva.

27. Xue, J., Liu, G.B., Dai, Q.H., Dang, X.H., \& Zhou, P. (2007). Effect of different vegetation restoration models on soil microbial biomass in eroded hilly loess plateau. Journal of Natural Resources, 22 (1), $20-27$ (in Chinese with English abstract).

28. Yu, Q. G., Chen, Y. X., Ye, X. Z., Zhang, Z. J., \& Tian, G. M. (2007). Influence of the DMPP (3, 4-dimethyl pyrazole phosphate) on nitrogen transformation and leaching in multi-layer soil columns. Chemosphere, 69, 825-831. 
Table 1: Physico-Chemical Parameters of IB-INW and IC-HAPI (Sihag et al., 2019) Zone

\begin{tabular}{|c|c|c|c|c|c|c|c|}
\hline \multirow[b]{2}{*}{ Parameters } & \multirow[b]{2}{*}{ Units } & \multicolumn{2}{|c|}{ IB-INW zone } & \multicolumn{2}{|c|}{ IC-HAPI zone } & \multirow[b]{2}{*}{ DI of FLS ${ }^{a}$} & \multirow[b]{2}{*}{ DI of $W L S^{b}$} \\
\hline & & $\begin{array}{c}\text { Mean } \\
\text { for FLS }\end{array}$ & $\begin{array}{c}\text { Mean } \\
\text { for WLS }\end{array}$ & $\begin{array}{c}\text { Mean } \\
\text { for FLS }\end{array}$ & $\begin{array}{c}\text { Mean } \\
\text { for WLS }\end{array}$ & & \\
\hline Sand & $\%$ & 53.15 & 81.68 & 83.85 & 90.77 & -57.76 & -11.12 \\
\hline Silt & $\%$ & 24.88 & 7.11 & 7.09 & 4.25 & +71.50 & +40.22 \\
\hline Clay & $\%$ & 21.97 & 11.2 & 9.04 & 4.97 & +58.85 & +55.62 \\
\hline $\mathrm{CaCO}_{3}$ & $\%$ & 3.41 & 2.07 & 4.95 & 3.28 & -45.16 & -58.45 \\
\hline CEC & meq/100g & 21.85 & 15.93 & 6.89 & 3.58 & +68.46 & +77.52 \\
\hline $\mathrm{pH}$ & - & 7.87 & 7.80 & 8.34 & 8.22 & -5.97 & -5.38 \\
\hline EC & $\mathrm{dS} \mathrm{m}^{-1}$ & 0.59 & 0.30 & 0.34 & 0.23 & +42.37 & +23.33 \\
\hline $\mathrm{OC}$ & $\%$ & 0.40 & 0.19 & 0.23 & 0.15 & +42.50 & +21.05 \\
\hline $\mathrm{OM}$ & $\%$ & 0.68 & 0.33 & 0.39 & 0.26 & +42.64 & +21.21 \\
\hline $\mathrm{N}$ & $\mathrm{kg} \mathrm{ha}^{-1}$ & 240.81 & 199.02 & 180 & 165.52 & +25.25 & +16.83 \\
\hline $\mathrm{P}$ & $\mathrm{kg} \mathrm{ha}^{-1}$ & 22.41 & 17.44 & 16.98 & 9.41 & +24.23 & +46.04 \\
\hline $\mathrm{K}$ & $\mathrm{kg} \mathrm{ha}^{-1}$ & 369.76 & 261.76 & 227.18 & 201.04 & +38.56 & +23.19 \\
\hline $\mathrm{Zn}$ & $\mathrm{ppm}$ & 0.56 & 0.43 & 0.51 & 0.47 & +8.92 & -9.30 \\
\hline $\mathrm{Fe}$ & $\mathrm{ppm}$ & 4.79 & 3.72 & 5.21 & 3.84 & -8.76 & -3.22 \\
\hline $\mathrm{Cu}$ & $\mathrm{ppm}$ & 0.42 & 0.35 & 0.36 & 0.25 & +14.28 & +28.57 \\
\hline $\mathrm{Mn}$ & $\mathrm{ppm}$ & 3.09 & 2.43 & 4.07 & 2.22 & -31.71 & +8.64 \\
\hline
\end{tabular}

a: DI values of FLS between IB-INW and IC-HAPI zone;

b: DI values of WLS between IB-INW and IC-HAPI zone



Figure1: Comparison Between IB-INW and IC-HAPI Zone

['OC: 0.46', 'N: 170', 'P: 9.8', 'K: 7', 'Zn: 0.24', 'pH: -0.2']

['OC: $-0.05^{\prime}$, 'N: 145', 'P: 3.0', 'K: 49', 'Zn: 0.07', 'Mn: 0.2 ', 'pH: -0.35 ']

['OC: 0.34 ', 'N: 185', 'P: 9.3', 'Fe: 0.7', 'Cu: 0.07', pH: -0.26]

['OC: 0.31', 'N: 206, 'P: 4.1', 'K: 45', 'Zn: 0.39', 'Fe: 0.4', 'Cu: 0.01', 'Mn: 0.4']

['OC: 0.37', 'N: 133', 'P: 7.8', 'K: 61', 'Fe: 3.1', 'Cu: 0.09', 'pH: -0.06 ']

Figure 2: Results of Chemical Parameters for Soil of IC-HAPI Zone by SFM Model

$$
\begin{aligned}
& \text { ['OC: } 0.36 \text { ', 'N: 59', 'P: } 3.8^{\prime}, \text { 'K: }-40 \text { ', 'Fe: } 0.6 \text { '] } \\
& \text { ['N: 17', 'P: 3.0', 'Zn: } 0.12^{\prime} \text { ] } \\
& \text { ['OC: } 0.17 \text { ', 'N: 37', 'P: 1.0', 'K: -44', 'pH: }-0.31 \text { '] } \\
& \text { ['OC: } 0.22 \text { ', 'N: 72', 'P: 1.9'] } \\
& \text { ['OC: } 0.28 \text { ', 'N: 63', 'P: } 0.5 \text { ', 'Zn: } 0.17 \text { '] }
\end{aligned}
$$

Figure 3: Results of Chemical Parameters for Soil of IB-INW Zone by SFM Model 
